\title{
1. Introduction: entrepreneurial trends meet entrepreneurial education
}

\section{Dafna Kariv, Harry Matlay and Alain Fayolle}

Projections for coming entrepreneurial trends predict that artificial intelligence (AI) will be a thriving area for innovation; the evolution of the Internet of things will have more impact on the economy; the digital twin will take on vast importance, and Blockchain technology promises to change applications in government, healthcare, content distribution, and the supply chain (Cearley et al., 2017; Armstrong, 2018). These innovations, among other emerging entrepreneurial endeavors, will result in vast market disruption and innovation-driven growth; in Bower and Christensen's (1995) terms, these trends encompass 'disruptive innovation'. While the entrepreneurial landscape is fraught with constant bursts of innovation that reciprocally propel development of progressive modes of production, technology and business dynamics, entrepreneurship education (EE) does not reflect these innovations. The expectation is that EE will provide the relevant entrepreneurial-driven knowledge, skills and abilities (KSAs), along with agile, creative mindsets and other psychological aspects (for example, self-effacement, motivation, intentions) to enable the implementation of such innovations into a viable, entrepreneurial business. However, research shows that EE for adult entrepreneurs still pursues conservative models, rather than forward-looking ones. This discrepancy between entrepreneurship and EE is echoed throughout the program types: the market is witnessing a gigantic outpouring of enabling systems (Matlay, 2006, 2008; Politis, 2005; Winkler et al., 2018), such as incubators, accelerators, academic programs for entrepreneurs, co-working spaces, corporate-based innovation centers, impact hubs, scaling accelerators, and digital accelerators, among others, but this substantial flux brings with it the question of relevant preparation for the entrepreneurial journey. The massively growing number of programs seems confusing to the learner-entrepreneurs, who need to determine which program will fit their needs as well as those of their stakeholders (Bischoff et al., 2018; Kariv et al., 2018; Steiner et al., 2018). Taken together, while entrepreneurship is characterized by vast 
innovation and boosted developments, the consequent implementation performance, which is attained through $\mathrm{EE}$, is lagging behind due to the existing conventional EE modalities. These incongruities are the impetus for this book's undertaking: to bring fresh views and perspectives on these prevailing gaps by illustrating innovative pedagogies and innovative programs through research studies, springing from an array of academic approaches, from various countries and various entrepreneurship programs.

Specifically, this book aims to bridge some of the existing and evolving gaps between the entrepreneurship landscape and EE, to introduce a 'disruptive innovation'-based look into $\mathrm{EE}$, thus providing the groundwork for a better, more vigorous fit between the learners' needs and EE focuses. This book offers new concepts and cases embodying EE and entrepreneurship learning (EL) in different countries, thereby covering a wide range of educational undertakings for entrepreneurs. The book aims to provide convergent, rather than divergent, perspectives on EE and EL. It sets out to deliver a constructive and focused research and learning agenda that closely matches the education and learning needs of nascent entrepreneurs and the corresponding programs that are being offered at all levels of the educational system.

\section{ENTREPRENEURSHIP EDUCATION}

EE embodies a unique educational niche that accentuates the learners' development of KSAs, mindsets and psychological competencies, and provides a more rigorous acquaintance with the ecosystem's dynamics to prepare and fortify learners who are starting or pursuing an entrepreneurial journey. Concurrently, research attests to EE's contribution to individuals' employability, thereby proving its value; yet, despite the proliferation of programs, EE has still not reached the expected goals.

The following areas present some challenges that have emerged in research, in embedding new educational modalities.

\section{The Vision and Goals}

- changing the vision of education to a meaningful experience;

- enabling daring, taking risks, failing;

- to be a continual process that adds more experiences, insights and knowledge as it progresses. 


\section{The Teaching Instructors}

- transformation of the teaching staff's role in class from delivering knowledge to enabling the learners' implementation of their vision;

- encouraging learners to dream, imagine, invent, provoke, create, change, act;

- placing the responsibility for the learning application on the learner.

\section{Innovation}

- embracing brand-new educational methods, e.g., digital learning, virtual reality, gamification;

- embedding technology in the educational experience;

- a boundless class: eliminating the limitations of time difference, distance, or learners' level of knowledge in class;

- combining fields and expertise to formulate new courses and programs.

(Kyrö, 2015; Lima et al., 2015; Nabi et al., 2017; Piperopoulos and Dimov, 2015.)

\section{WHAT DOES ENTREPRENEURSHIP EDUCATION ENTAIL?}

Entrepreneurs require broader learning spheres, embodied in the term: 'space'; both their dynamic, creative and proactive nature and the actual conditions that they encounter, that is, full commitment of time, money and emotional engagement required to develop their business, converge into a more customized and flexible 'space' for effective EE and EL (Esmi et al., 2015; Gemmell, 2017; Wahid et al., 2017). Researchers and educators are driven to develop new educational forms to meet both entrepreneurial developments and the entrepreneurs' need for customized EE (Béchard and Grégoire, 2005; Fayolle and Gailly, 2008; Kariv, forthcoming; Kuratko, 2005).

Such leading endeavors are exhibited in various educational forms: experiential learning (Kolb and Kolb, 2009) introduced through an active, experience-based learning process; 'real world' simulations, intertwining experiences with cutting-edge stores of knowledge, to provide a platform to simulate the entrepreneurial journey; and programs conveying 'transferable' and 'generic' KSAs, which are context-dependent and process-based, thus the learning outcomes can be replicated and transferred to any 
situation (content-dependent), while catering to an agile platform for EE (Bennis and O'Toole, 2005; Brockbank and McGill, 2007; Brush et al., 2015; Morris et al., 2013; Pfeffer and Fong, 2002). Our book assembles vibrant, successful empirical cases, springing from different theoretical approaches, that represent the richness of the field of $\mathrm{EE}$ in its endeavor to echo the dynamic entrepreneurial landscape.

\section{A COMPOUND OUTLOOK INTO ENTREPRENEURSHIP EDUCATION}

While it is well-established that EE must reinvent itself to reflect and support entrepreneurial developments, the right way to do this is still under debate. Entrepreneurship is multifaceted, and EE should reflect this by compounding different disciplinary fields, rather than founding EE in business schools; a more valuable education 'package' can be created through an analysis of entrepreneurial situations, by embedding approaches from the social sciences, health-related areas or philosophy, for example. Delivery methods should embrace a large scope of methodologies, such as hackathons, online learning, gamification, internships; target learners can introduce innovation and better learning outcomes in meeting the learner-entrepreneurs' changing needs. A fusion of learners from different disciplines, sectors, schools and levels (undergraduate, graduate, doctoral students, alumni) adds to the educational process's diversity, while a blended teaching staff, for example academic professors, serial entrepreneurs, venture capitalists and angels, leading individuals from government, as well as students in peer sessions, can enrich the program and its value.

Research shows that programs based on a single 'manifestation', that is, delivering only knowledge, only coaching, and so on, do not reach highlevel learning outcomes; thus EE should rely on a larger, compounded base (Fayolle and Gailly, 2015; Katz, 2003; Krueger, 2009; Peterman and Kennedy, 2003; Souitaris et al., 2007). EE should be transformed into a smart, facilitating platform that provides a fusion of thematic (for example, Blockchain, health, tourism), entrepreneurship- and business-related KSAs, intentions and mindsets to encourage entrepreneurs to consume EE throughout the different stages of their businesses; the development of customized EE is imperative (Bae et al., 2014; Lackéus and Williams Middleton, 2015; Rauch and Hulsink, 2015; Walter and Block, 2016; Zeng and Honig, 2016). 


\section{INNOVATIVE FORMS OF ENTREPRENEURSHIP EDUCATION}

The mounting research attention to the vital effect of EE on learners, teaching staff and stakeholders, as well as its contribution to innovation, research and further global development, prompted us to study various EE programs and thoroughly inspect their impact. This book thus offers contributions from leading researchers representing a wide variety of perspectives on, and approaches to, EE, portraying various programs derived from different countries, for example, the United States, Australia, European countries, Israel and Pakistan, and originating from diversified qualitative and quantitative research approaches.

Part I, 'The key role of entrepreneurial pedagogies', introduces a fresh look at EE with contributions on the role of design, participant-centered approaches, and psychological aspects in the creation of an innovative pedagogy. Chapter 2, authored by Penaluna and Penaluna, from Swansea, "I'm a designer, get me out of here": can entrepreneurial education advance through learning from design education?', discusses the relationship between design and EL by focusing on new areas, such as 'designerly thinking' and 'designerly ways of knowing', in education aimed at developing the business. This is followed by Rice and Stitt's chapter, 'A portfolio of integrative and reinforcing pedagogies', which examines a participant-centered learning, iterative process of course development, drawing on a pedagogical system tailored for mid-career, working professionals. The program delivers a learning experience and utilizes a comprehensive portfolio of pedagogical techniques. The fourth and fifth chapters delve into more psychologically driven aspects, which are still scarce in EE. Chapter 4, contributed by Huxtable-Thomas and Hannon, 'Beyond content and pedagogy: the role of self and place in entrepreneurial leadership development', provides an in-depth look through a quantitative study exploring the question 'What does education mean in the context of entrepreneurship?' and proves the relevance of the learner's desires or preferences in aligning the content and pedagogy, including the learner's perceived self-identity and expectations of learning. Chapter 5 by O'Dwyer, Costin and Hynes, 'Explicit and tacit knowledge transfer in entrepreneurial education: the Method Approach', wraps up the first part of the book by revealing, through qualitative, in-depth interviews, the significance of five linked constituent elements of the Method Approach: play, empathy, creation, experimentation and reflection, to effective EL by transitioning knowledge to the applied interpretation of entrepreneurship as practice. Fueled with insights on the new pedagogy that is beginning to evolve, Part II, 'Why do entrepreneurship teachers 
matter?', carries the investigation a step further. Chapter 6, 'A study of the entrepreneurship education curriculum adaptation process among in-service vocational education teachers', authored by Asghar, Kyrö and Gul, introduces, through an exploratory research method, the process of entrepreneurship curriculum adaptation among in-service teachers of vocational education in Pakistan, revealing that EE that enhances entrepreneurial KSAs can be achieved through creative content adaptation, versatile pedagogical skills and a school climate linked with the entrepreneurial ecosystem. Chapter 7 probes the teacher level from a school view. Written by Seikkula-Leino, Ruskovaara, Pihkala, Diego Rodríguez and Delfino, 'Developing entrepreneurship education in Europe: teachers' commitment to entrepreneurship education in the UK, Finland and Spain', reports on a qualitative, multinational study of 61 teachers from the UK, Spain and Finland, focusing on teachers' commitment to EE in Europe and its variations. It reveals that teachers' training for EE should be further developed. Underscoring the variations among the investigated countries, the chapter sheds light on teachers' commitment by attesting to the need for teachers to take an active role in the development of EE. Deepening our insights, from the teacher's perspective in Chapter 7 to the individual's perspective in Chapter 8, are Hietanen and Ruismäki, 'Enhancing students' latent nascent entrepreneurship in basic education'. Based on three case studies from Finland, this chapter discusses the kind of $\mathrm{EE}$ and environments needed to develop entrepreneurial intentions among students, stressing the dilemma posed by contrasting results on the crucial role of entrepreneurship knowledge to entrepreneurial intentions vis-à-vis findings on the weak and implausible knowledge held by teachers on entrepreneurship. Teachers' knowledge is crucial for EE viability and value. In Chapter 9, 'Teachers as role models in entrepreneurship education: perspectives from the point of view of entrepreneurs', by San-Martín, Fernández-Laviada and Pérez, the teacher's role is revealed by a focus group consisting of 11 entrepreneurs from the region of Cantabria, Spain. The authors show how teachers inspire, influence and lead the future career choices of their students. Part III of the book expands the boundaries of our exploration into 'The effectiveness of entrepreneurship education'. Opening with a quantitative study by two UK universities, Chapter 10, 'Providing effective entrepreneurship education: a UK perspective', contributed by Jones, Pickernell, Connolly and Netana, imparts the value and design of EE and its impact on both self-employability and career choices. Curriculum focuses and delivered contents affect learners' future employability; respondents determined the relevant competencies that provided pertinent knowledge to assist in the development and activity of firms in international markets. A 
theoretical look that deepens our understanding of competencies and their measurement is reviewed in Chapter 11, 'The assessment of transversal competences in entrepreneurship education', by Luppi and Bolzani. Embracing an interdisciplinary perspective, this theoretical review reveals that student performance in entrepreneurial competencies can be assessed through a holistic view, including a thorough look into the learning environment and learning outcomes, to facilitate interactive, effective and active learning. Through a process of reflective practice, Jones and Matlay in Chapter 12, 'Entrepreneurship education as perspective transformation', provide the Australian viewpoint on learners' needs embedded in programs to engage them in EE. Based on a single-site case study at the University of Tasmania, Australia, with direct observation over a 14-year period, and an initial and ongoing interaction with the published literature, peer observation by colleagues, and mentor feedback, the authors urge us to pay attention to the general and immediate needs of the student, which requires an alternative approach that is not dominated by the pedagogical influence of the educator, but rather allows students to create concepts and ideas through personal experience and learn through entrepreneurship. The Canadian view concludes Part III, with Chapter 13, 'Over one hundred years in management education: the evolution processes of academic entrepreneurship', by Keen, SanchezFamoso, Cisneros and Mejia-Morelos, which provides an analysis of the case of HEC Montréal to reveal the development of entrepreneurial forms. Multidisciplinary teaching, experiential activities, international programs, coaching and mentorship support, online education, cuttingedge tools and approaches based on effectuation, networking events, testimonies of entrepreneurs, competitions and contests, and financial and emotional support converge to form the holistic scope of the HEC program. Faculty members play three roles - as researchers, professors and facilitators - in supporting entrepreneurial projects. The next four chapters make up Part IV of the book, 'Innovative programmes in entrepreneurship education'. This part opens with Chapter 14, 'The Rising Tide Angel Training Program: education for the ecosystem (not just for the entrepreneur!)', contributed by Coleman and Robb, which provides a comprehensive depiction of the first Rising Tide Angel Training Program cohort in the US, pointing to the untapped pool of women with both the financial means and the desire to become angel investors. The chapter identifies the value of portraying women's motivations to enroll in the program in order to attract the next cohorts for the program, such as the opportunity to become part of an investing network of like-minded women investors and to expand the entrepreneurial ecosystem in ways that will benefit women entrepreneurs. The role of the 
educational and networking activities embedded in the Rising Tide Program are also perceived as key elements of the participants' learning experience. This innovative program is followed by another, described in Chapter 15, 'University business incubators: mechanisms to transform ideas into businesses', by Redondo and Camarero. Drawing on data collected from 93 incubation programs from Spanish and Dutch universities, the relationships among the incubators' characteristics, their managers' characteristics, the services offered by incubators and the success of the incubation programs were statistically tested through partial least squares structural equation modeling (PLS-SEM) with SmartPLS computer software. A wide range of services and incubator managers' experience in business and science were found to affect the success of the incubation programs. A disruptive innovation case depicting the Israeli view is illustrated in Israel-Cohen and Kaplan's Chapter 16, 'Prospects and challenges of disruptive innovation in the management and social science academic curriculum: a case study approach', a journey through the curriculum-building process, laying out the rationale for the vision followed by a descriptive analysis of two models of innovative teaching methods piloted at the College of Management Academic Studies, Israel: Experiential Distance Learning (EDL) and Personalized Project-Based Learning (PPBL). The authors argue that while investing efforts in experimentation with disruptive forms of innovation within the classroom is vital for the learners, analyses prove the instructors' reluctance and ineptitude in transforming themselves from 'dispensers of knowledge' to mentors and facilitators, and the students' reluctance to simultaneously develop critical thinking and problem solving. An institutional combination of reflective experimentation with disruptively innovative courses using a clear implementation process coupled with EE training for faculty members across disciplines may provide the turning point. Chapter 17 concludes our book with 'Educating sustainable entrepreneurship: the case of the University of Groningen', introducing the Dutch view as contributed by de Jong. The chapter covers the questions of why and how the new program facilitates the development of academic research skills alongside leadership and entrepreneurship competencies, by presenting an in-depth case study of a new academic Master's program in the Netherlands, and concluding that a very specific aim and strategy contribute to the program's success: engaging the ecosystem, including the government, in innovative programs, and identifying and meeting market demands for new talent. 


\section{REFERENCES}

Amstrong, P. (2018). These are the startups you should watch in 2018, Forbes. com, 8 January, available at: https://www.forbes.com/sites/paularmstrongtech/20 18/01/08/these-are-the-startups-you-should-watch-in-2018/.

Bae, T.J., Qian, S., Miao, C. and Fiet, J.O. (2014). The relationship between entrepreneurship education and entrepreneurial intentions: A meta-analytic review. Entrepreneurship Theory and Practice, 38(2), 217-54.

Béchard, J.P. and Grégoire, D. (2005). Entrepreneurship education research revisited: The case of higher education. Academy of Management Learning \& Education, 4(1), 22-43.

Bennis, W.G. and O'Toole, J. (2005). How business schools lost their way. Harvard Business Review, 83(5), 96-104.

Bischoff, K., Volkmann, C.K. and Audretsch, D.B. (2018). Stakeholder collaboration in entrepreneurship education: An analysis of the entrepreneurial ecosystems of European higher educational institutions. The Journal of Technology Transfer, 43(1), 20-46.

Bower, J.L. and Christensen, C.M. (1995). Disruptive technologies: Catching the wave. Harvard Business Review, 73(1), 43-53.

Brockbank, A. and McGill, I. (2007). Facilitating Reflective Learning in Higher Education. Maidenhead: McGraw-Hill Education.

Brush, C., Neck, H. and Greene, P. (2015). A practice-based approach to entrepreneurship education. In V. Crittenden, K. Esper, N. Karst and R. Slegers (eds), Evolving Entrepreneurial Education: Innovation in the Babson Classroom. Bingley: Emerald Group, pp. 35-54.

Cearley, D., Burke, B., Searle, S. and Walker, M. (2017). Top 10 strategic technology trends for 2018, Gartner.com, 3 October 2017, available at: https://www. gartner.com/doc/3811368.

Esmi, K., Marzoughi, R. and Torkzadeh, J. (2015). Teaching learning methods of an entrepreneurship curriculum. Journal of Advances in Medical Education \& Professionalism, 3(4), 172.

Fayolle, A. and Gailly, B. (2008). From craft to science: Teaching models and learning processes in entrepreneurship education. Journal of European Industrial Training, 32(7), 569-93.

Fayolle, A. and Gailly, B. (2015). The impact of entrepreneurship education on entrepreneurial attitudes and intention: Hysteresis and persistence. Journal of Small Business Management, 53(1), 75-93.

Gemmell, R.M. (2017). Learning styles of entrepreneurs in knowledge-intensive industries. International Journal of Entrepreneurial Behavior \& Research, 23(3), 446-64.

Kariv, D. (forthcoming). Educating Entrepreneurs, New York: Routledge.

Kariv, D., Cisneros, L. and Ibanescu, M. (2018). The role of entrepreneurial education and support in business growth intentions: The case of Canadian entrepreneurs. Journal of Small Business \& Entrepreneurship, pp. 1-27.

Katz, J.A. (2003). The chronology and intellectual trajectory of American entrepreneurship education: 1876-1999. Journal of Business Venturing, 18(2), 283-300.

Kolb, A.Y. and Kolb, D.A. (2009). Experiential learning theory: A dynamic, holistic approach to management learning, education and development. In: 
S. Armstrong and C. Fukami (eds), The SAGE Handbook of Management Learning, Education and Development, London: Sage, pp. 42-68.

Krueger, N.F. (2009). The microfoundations of entrepreneurial learning and ... education: The experiential essence of entrepreneurial cognition. In: G. Page West III, E.J. Gatewood and K.G. Shaver (eds), Handbook of University-wide Entrepreneurship Education. Cheltenham, UK and Northampton, MA, USA: Edward Elgar Publishing, pp. 35-59.

Kuratko, D.F. (2005). The emergence of entrepreneurship education: Development, trends, and challenges. Entrepreneurship Theory and Practice, 29(5), 577-97.

Kyrö, P. (2015). The conceptual contribution of education to research on entrepreneurship education. Entrepreneurship \& Regional Development, 27(9-10), 599-618.

Lackéus, M. and Williams Middleton, K. (2015). Venture creation programs: Bridging entrepreneurship education and technology transfer. Education + Training, 57(1), 48-73.

Lima, E., Lopes, R.M., Nassif, V. and Da Silva, D. (2015). Opportunities to improve entrepreneurship education: Contributions considering Brazilian challenges. Journal of Small Business Management, 53(4), 1033-51.

Matlay, H. (2006). Researching entrepreneurship and education: Part 2: What is entrepreneurship education and does it matter? Education + Training, 48(8/9), 704-18.

Matlay, H. (2008). The impact of entrepreneurship education on entrepreneurial outcomes. Journal of Small Business and Enterprise Development, 15(2), 382-96.

Morris, M.H., Webb, J.W., Fu, J. and Singhal, S. (2013). A competency-based perspective on entrepreneurship education: Conceptual and empirical insights. Journal of Small Business Management, 51(3), 352-69.

Nabi, G., Liñán, F., Fayolle, A., Krueger, N. and Walmsley, A. (2017). The impact of entrepreneurship education in higher education: A systematic review and research agenda. Academy of Management Learning \& Education, 16(2), 277-99.

Peterman, N.E. and Kennedy, J. (2003). Enterprise education: Influencing students' perceptions of entrepreneurship. Entrepreneurship Theory and Practice, 28(2), $129-44$.

Pfeffer, J. and Fong, C.T. (2002). The end of business schools? Less success than meets the eye. Academy of Management Learning \& Education, 1(1), 78-95.

Piperopoulos, P. and Dimov, D. (2015). Burst bubbles or build steam? Entrepreneurship education, entrepreneurial self-efficacy, and entrepreneurial intentions. Journal of Small Business Management, 53(4), 970-85.

Politis, D. (2005). The process of entrepreneurial learning: A conceptual framework. Entrepreneurship Theory and Practice, 29(4), 399-424.

Rauch, A. and Hulsink, W. (2015). Putting entrepreneurship education where the intention to act lies: An investigation into the impact of entrepreneurship education on entrepreneurial behavior. Academy of Management Learning \& Education, 14(2), 187-204.

Souitaris, V., Zerbinati, S. and Al-Laham, A. (2007). Do entrepreneurship programmes raise entrepreneurial intention of science and engineering students? The effect of learning, inspiration and resources. Journal of Business Venturing, 22(4), 566-91.

Steiner, S.D., Brock, D.D., Pittz, T.G. and Liguori, E. (2018). Multi-disciplinary involvement in social entrepreneurship education: A uniquely threaded ecosystem. Journal of Ethics \& Entrepreneurship, 8(1), 73-91. 
Wahid, A., Ibrahim, A. and Hashim, N.B. (2017). The review of teaching and learning on entrepreneurship education in institution of higher learning. Journal on Technical and Vocational Education, 1(2), 82-8.

Walter, S.G. and Block, J.H. (2016). Outcomes of entrepreneurship education: An institutional perspective. Journal of Business Venturing, 31(2), 216-33.

Winkler, C., Saltzman, E. and Yang, S. (2018). Improvement of practice in entrepreneurship education through action research: The case of coworking at a nonresidential college. Entrepreneurship Education and Pedagogy, 1(2), 139-65.

Zeng, Z. and Honig, B. (2016). How should entrepreneurship be taught to students with diverse experience? A set of conceptual models of entrepreneurship education. In J. Katz and A. Corbett (eds), Models of Start-up Thinking and Action: Theoretical, Empirical and Pedagogical Approaches. Bingley: Emerald Group, pp. 237-82. 